Annales Geophysicae (2001) 19: 975-984 (C) European Geophysical Society 2001

\title{
Seasonal variation of vertical eddy diffusivity in the troposphere, lower stratosphere and mesosphere over a tropical station
}

\author{
D. Narayana Rao, M. V. Ratnam, T. N. Rao, and S. V. B. Rao \\ Department of Physics, Sri Venkateswara University, Tirupati 517 502, India. \\ Received: 25 August 2000 - Revised: 16 March 2001 - Accepted: 26 April 2001
}

\begin{abstract}
Long-term VHF radar $\left(53 \mathrm{MHz}\right.$ with $3^{\circ}$ beamwidth) observations at Gadanki $\left(13.5^{\circ} \mathrm{N}, 79.2^{\circ} \mathrm{E}\right)$, India, during the period from September 1995 to August 1999 are used to study monthly, seasonal and annual medians of vertical eddy diffusivity, $K$ in the troposphere, lower stratosphere and mesosphere. First, the spectral width contribution due to non-turbulent effects has been removed for further analysis and the monthly, seasonal medians of $K$ are calculated. The monthly median of $K$ in the troposphere shows maximum and minimum in June-July and November-December, respectively. In general, large values of $K$ are seen up to 10 $\mathrm{km}$ and then decrease with height. Larger values of $K$ are observed during monsoon and post-monsoon than in winter and summer. In general, the maximum and minimum values of the annual median of $K$ (in logarithmic values) in the troposphere are found to be 0.25 and $-1.3 \mathrm{~m}^{2} \mathrm{~s}^{-1}$ respectively. In the mesosphere, the monthly median of $K$ shows maximum and minimum during June-July and November-December, respectively, similar to the lower atmosphere. The value of $K$ in the mesosphere becomes larger and it increases with height up to $75 \mathrm{~km}$ and again decreases above that height. The maximum values are seen during the summer, followed by equinoxes and a minimum during the winter. In general, the maximum and minimum values of $K$ (in logarithmic values) are found to be 0.7 and $0.3 \mathrm{~m}^{2} \mathrm{~s}^{-1}$, respectively, in the mesosphere. A comparison of Doppler spectral parameters in different beam directions shows anisotropy in both signalto-noise ratio (SNR) and spectral widths in the mesosphere, whereas it shows isotropy in SNR and anisotropy in the spectral widths in troposphere and lower stratosphere.
\end{abstract}

Key words. Meteorology and atmospheric dynamics (middle atmosphere dynamics; turbulence; waves and tides).

\section{Introduction}

Knowledge of the vertical eddy diffusivity, $K$, is very essential because it is one of the important parameters in atmo-

Correspondence to: D. Narayana Rao

(profdnrao@usa.net) spheric studies. Various techniques have evolved in order to study eddy diffusivity, which includes rocket (Lübken et al., 1987), and air-craft (Lilly et al., 1974) observations. Studies of Woodman and Guillen (1974) triggered the evolution of a new generation of VHF/UHF radars and are extensively used for the characterization of turbulence due to their high temporal and spatial resolutions. Although the theory for deriving $K$ from radar measurements has been developed long ago (Sato and Woodman, 1982), the follow-up implementation has been slow due to various reasons (Hocking, 1997). Most of these reasons are solved and reviewed by Hocking (1983, 1985, 1986, 1997).

There are two methods proposed for the estimation of $K$ from the radar measurements. These methods assume that the turbulence is isotropic and is in the inertial sub-range. Furthermore, it is also assumed that the spectrum follows a kolmogoroff shape and the atmosphere is stable and stratified $\left(N^{2}>0\right)$. The first method uses the radar-backscattered power for the quantification of turbulence. The second method uses the spectral width of the backscattered echo for the estimation of $K$. This method is used in the present study and is described in detail in Sect. 2. These two methods are extensively compared (Cohn, 1995) and a reasonably good agreement has been found between the two methods. However, primarily two non-turbulent effects, beam broadening and shear broadening, contaminate the observed spectral width. Beam broadening effects will occur only for a vertical pointing beam and shear broadening will occur in all beams. Before going to the actual calculation of eddy diffusivity using the width method, effects due to non-turbulent parameters should be removed. The theory to remove these effects has been well developed and discussed extensively by Atlas et al. (1969), Frisch and Clifford (1974), Sato and Woodman (1982), Hocking (1983,1985,1986), Fukao et al. (1994), Nastrom (1997) and will not be discussed here.

Most of the studies on eddy diffusivity are based on observations of short duration, except for a few climatological studies. Moreover, these studies are confined to midand high latitudes. Fukao et al. (1994) studied the seasonal variation of vertical eddy diffusivity in the MST region using three years of data collected with MU radar. Nastrom 
and Eaton (1997) studied the climatology of eddy diffusivity using the VHF radar observations at WSMR, New Mexico. Hocking (1988) measured the turbulence parameters in the upper mesosphere and lower thermosphere with a 2-MHz narrow beam radar for about two years over Adelaide, Australia. In the tropics, detailed studies of turbulence parameters are sparse, except a few by Rao et al. (1997) using a small data set and Rao et al. (2001) using three years of radar data. But in both the studies, results are confined only to troposphere and lower stratosphere. Moreover, the knowledge of $K$ is necessary at various geographical locations in order to understand the global circulation. In this paper, data collected with the Indian MST radar for about three years in the troposphere and lower stratosphere, and for about four years in the mesosphere is used to study monthly, seasonal and annual variations of vertical eddy diffusivity and the results are presented.

\section{System description and database}

The Indian MST radar is a very high power monostatic coherent pulsed Doppler radar operating at $53 \mathrm{MHz}$ with a peak power aperture product of $3 \times 10^{10} \mathrm{Wm}^{2}$ and is located at Gadanki $\left(13.5^{\circ} \mathrm{N}, 79.2^{\circ} \mathrm{E}\right)$, a tropical station in India. The antenna occupying an area of $130 \mathrm{~m} \times 130 \mathrm{~m}$ is a phased array of $32 \times 32$ three element Yagi antennas consisting of two orthogonal sets, one for each polarization (magnetic E-W and $\mathrm{N}-\mathrm{S}$ ). It generates a radiation pattern with the main lobe of a $3^{\circ}$ width (between $3 \mathrm{~dB}$ points), a gain of $36 \mathrm{~dB}$ and a first side lobe level of $-20 \mathrm{~dB}$. The main beam can be positioned at any look angle within $\pm 20^{\circ}$ off the zenith in two major planes (E-W and N-S) with $1^{\circ}$ intervals. The number of FFT points are up to 512 and coherent integrations are from 4 to 512 (selectable in binary steps). The uncoded pulse widths can be from $1 \mu \mathrm{s}-32 \mu \mathrm{s}$ (in binary steps) and the coded ones, $16 \mu \mathrm{s}$ and $32 \mu \mathrm{s}$ with $1 \mu \mathrm{s}$ baud length. More details of the system description can be found in Rao et al. (1995) and Kishore (1995).

The radar parameters used for the present study are given in Table 1. The values in brackets are for mesospheric heights The received echo signals were sampled at intervals of 150 $\mathrm{m}(1.2 \mathrm{~km})$ in the height range of $7.5-21 \mathrm{~km}(65-85 \mathrm{~km})$ and were coherently integrated over 128 (64) pulses of transmission. The complete time series of the decoded and integrated signal samples are subjected to FFT for the on-line computation of the Doppler power spectra for each range bin. The offline data processing for the parameterization of the Doppler spectra involves the removal of dc, an estimation of the average noise level, incoherent integration (if any) and the computation of the three low order moments. For estimating the average noise level, an objective method developed by Hildebrand and Sekhon (1974) has been adopted here.

The data used for the present study is depicted in Fig. 1. The top panel is for the troposphere and the bottom panel is for the mesosphere. In the troposphere and lower stratosphere, radar data collected for about 30 minutes a day at

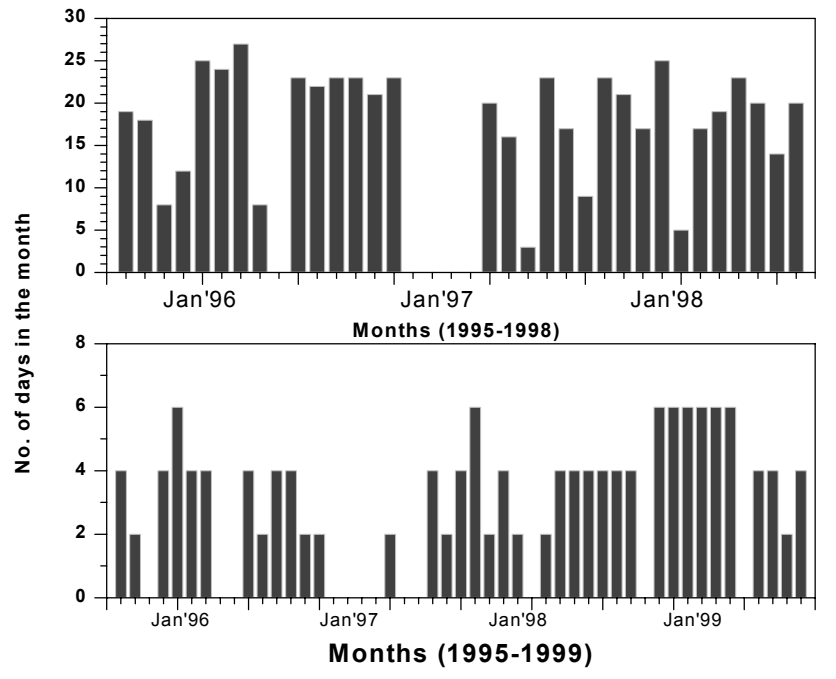

Fig. 1. Indian MST radar observations used for the present study in the troposphere and lower stratosphere (upper panel) and mesosphere (bottom panel).

around 1700 LT (1200 GMT) from September 1995 to August 1998 are taken. As seen from the figure, in most of the months, data is available for more than 15 days covering the total month. For the mesosphere, data collected with the MST radar from September 1995 to August 1999 is used to study the monthly and seasonal variation of eddy diffusivity. For the mesospheric studies, the MST radar is operated in two modes. In the first mode, radar is operated continuously from $1030 \mathrm{LT}$ to $1630 \mathrm{LT}$. In the second mode, radar is operated for about 10 minutes an hour, starting from $1000 \mathrm{LT}$ until the next day at 1000 LT. However, we have only used the data collected during the daytime in the present study. The methodology used for the estimation of $K$ for the present study is briefly discussed in the next section.

\section{Methodology}

The observed radar spectral width is primarily contaminated by beam broadening and shear broadening effects. Atlas (1969) originally discussed these effects and presented some formulae, but they are only applicable for narrow beams. Later, it was extensively developed by Hocking $(1983,1985$, 1987, 1988 and 1997). Fukao et al. (1994) treated these effects separately. Later, generalized formulae were presented by treating all the effects in the single equation (Nastrom, 1997; Nastrom and Eaton, 1997). The spectral broadening due to finite beam width and vertical shear is given by Nastrom (1997)

$$
\begin{aligned}
\sigma^{2} \approx & \frac{\theta^{2}}{3} u_{o}^{2} \cos ^{2} \alpha-\frac{2 \theta^{2}}{3} \sin ^{2} \alpha\left(u_{o} \frac{\partial u}{\partial z} R_{o} \cos \alpha\right) \\
& +\frac{\theta^{2}}{24}(3+\cos 4 \alpha-4 \cos 2 \alpha)\left(\frac{\partial u}{\partial z}\right)^{2} R_{o}^{2}
\end{aligned}
$$


Table 1. Experimental specifications used for the present study

\begin{tabular}{lll}
\hline Specification & $\begin{array}{l}\text { Troposphere and Lower } \\
\text { Stratospheree }\end{array}$ & Mesosphere \\
\hline Pulse width & $16 \mu$ s (coded) & $8 \mu$ s (uncoded) \\
Inter pulse period & $1000 \mu \mathrm{s}$ & $1000 \mu \mathrm{s}$ \\
Range relolution & $150 \mathrm{~m}$ & $1.2 \mathrm{~km}$ \\
Time resolution & $72 \mathrm{~s}$ & $65 \mathrm{~s}$ \\
Range & $7.5-21 \mathrm{~km}$ & $65-85 \mathrm{~km}$ \\
Beam directions & Six & Five \\
& $(\mathrm{E}, \mathrm{W}, \mathrm{Zen}-\mathrm{Y}, \mathrm{Zen}-\mathrm{X}, \mathrm{N} \& \mathrm{~S})$ & $(\mathrm{E}, \mathrm{W}, \mathrm{Zen}-\mathrm{Y}, \mathrm{N} \& \mathrm{~S})$ \\
Beam width & $3^{\circ}$ & $3^{\circ}$ \\
Coherent integratons & 128 & 64 \\
Incoherent integrations & 1 & 1 \\
FFT points & 128 & 128 \\
\hline
\end{tabular}

$$
+\left(\frac{\theta^{2}}{3} \cos 4 \alpha+\sin ^{2} \alpha \cos ^{2} \alpha\right)\left(\frac{\partial u}{\partial z}\right)^{2} \frac{\Delta R^{2}}{12}
$$

where $\theta$ is the half-beam width $\left(1.5^{\circ}\right), u_{o}$ is the horizontal wind component along the radar beam, $\alpha$ is the off-vertical beam angle $\left(10^{\circ}\right), R_{o}$ is the range, $\partial u / \partial z$ is the wind shear of the horizontal wind and $\Delta R$ is the range resolution. Here it is noted that all the terms on the right-hand side of Eq. (1), except the last part of the last term, depend on the beam-width, thus representing beam-broadening effects. The first term in the equation is due to beam-broadening effects by the background wind. The second, third, and fourth terms are due to the combined effects of finite beam-width and vertical wind shear. Terms two and three depend on the range as well as on the vertical wind shear. Term four represents the variance due to wind speed changes simultaneously along and across the beam, and the term five originates from wind speed changes along the beam. For details of the equation and procedure, please refer Nastrom (1997).

After subtracting these effects from the observed width, we will obtain the spectral width due to turbulence alone and from this width (after correction), eddy diffusivity can be calculated using the following equation

$K \approx 0.1 \frac{\sigma^{2}}{N}$

where $N$ is the Brunt-vaisala frequency and is estimated from temperature measurements. Three years of temperature observations in the troposphere and lower stratosphere, required for estimating the Brunt-Vaisala frequency, are collected from the Indian Meteorological Department at Chennai, which is at a radial distance of $120 \mathrm{~km}$ from the radar site. For the mesosphere, temperature data is taken from Nd:YAG lidar, which is located at the radar site. Every month, four nights of lidar temperature data is averaged and treated as representative temperature for that month. Here it is noted that $N$ is a slow varying component of the mean field and the value of $K$ depends primarily on the observed spectral width itself and not on the temperature (Fukao et al., 1994). The spectral width is calculated for every $150 \mathrm{~m}$ in the troposphere and lower stratosphere with a time resolution of $72 \mathrm{~s}$, and for every $1.2 \mathrm{~km}$ in the mesosphere with a time resolution of $65 \mathrm{~s}$.

\section{Results and discussion}

In the present study, the method given by Nastrom (1997) is used for the estimation of the vertical eddy diffusivity $K$. First, the non-turbulent contributions have been removed from the observed spectral width. On occasions when turbulence is weak and also during strong wind conditions, the correction becomes more than the observed width, which is unrealistic. In nearly $30 \%$ of the cases, it is observed that the correction becomes more than the observed width. In order to include all the values, the median of $K$ has been used instead of the mean in the present study.

Figures $2 \mathrm{a}$ and $\mathrm{b}$ show typical scatter plots of spectral width contamination due to non-turbulent effects versus the observed spectral half-power half width in the troposphere and lower stratosphere on a day during the monsoon (4 July 1996) and winter (11 December 1995) seasons. Note that the square of the width is given for the lower atmosphere. From the figure it is clear that in July, at most of the heights, the correction seems to be less than the observed spectral width in the height region of $7.5-14 \mathrm{~km}$ whereas, the correction is more than the observed width in the height region of 14-21 $\mathrm{km}$. During December, the experimental width is found to be greater than the correction at most of the heights. Figures $2 \mathrm{c}$ and d show typical scatter plots of observed spectral widths versus width due to non-turbulent effects in the mesosphere on a day during the summer (26 July 1999) and winter (14 December 1998) seasons. During the winter season, the correction is substantially less when compared to the observed width at most of the heights. But during the summer season, 


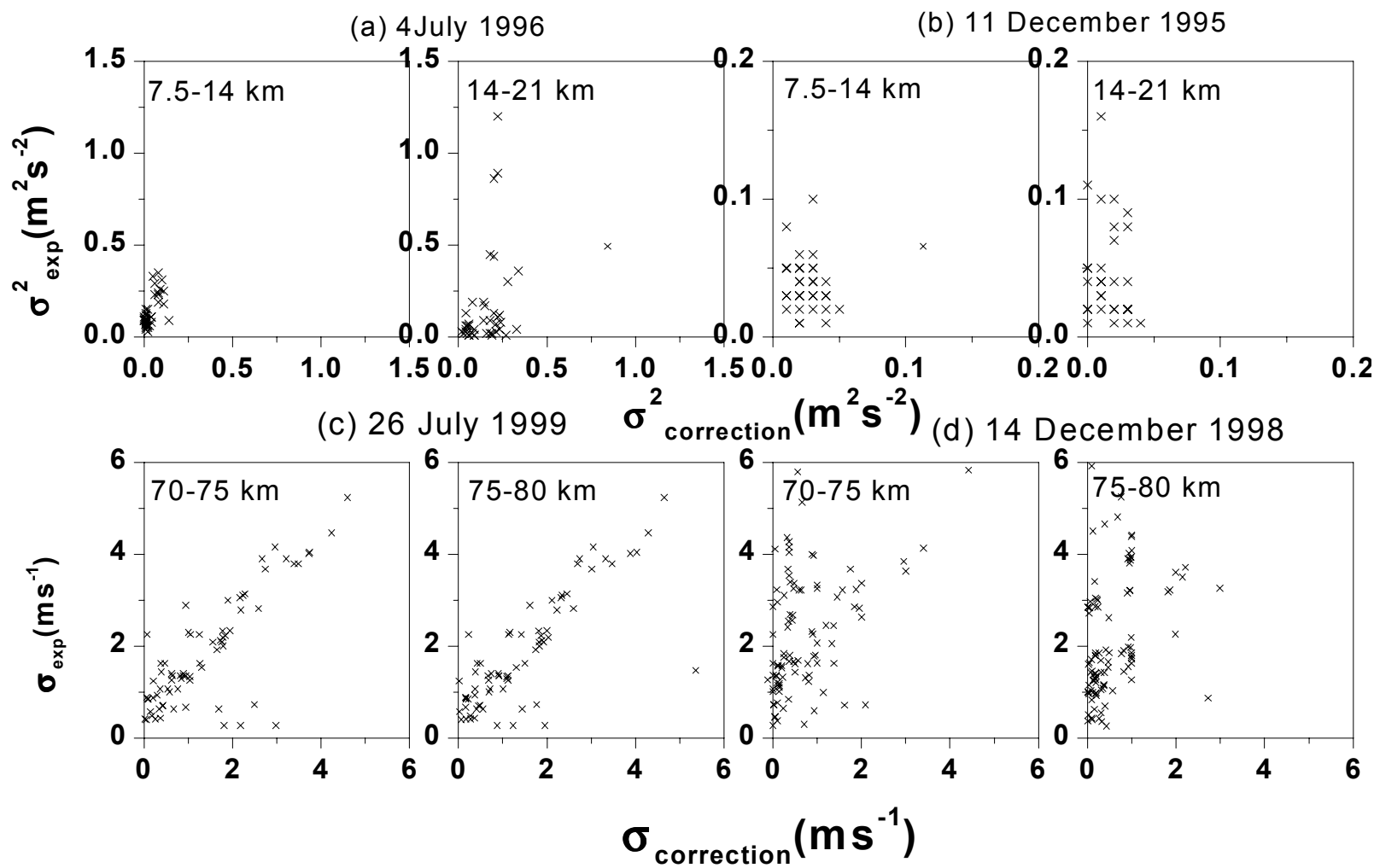

Fig. 2. Typical scatter plots between experimental width and the correction observed in the troposphere and lower stratosphere on (a) 4 July 1996, (b) 11 December 1995 (top panel) and in the mesosphere on (c) 26 July 1999 and (d) 14 December 1998 (bottom panel).

the correction seems to be greater.

\subsection{Comparison of Doppler spectral parameters in different beam directions}

Figure 3 (top panel) shows the comparison of the SNR and the spectral width in the north and east beam directions in the troposphere and lower stratosphere plotted using the data from September 1995 to August 1996. A total of 16654 data points using a $150 \mathrm{~m}$ range resolution between 7.5 to $21 \mathrm{~km}$ is used. From the figure it is clear that in the lower atmosphere, the SNR is almost equal in both directions which show isotropy. But the spectral width is observed to be more in the north beam for about $40 \%$ of the time, whereas it is more in the east beam for about $30 \%$ of time, and it is nearly equal in both the directions for about $30 \%$ of time showing some anisotropy. These results are somewhat different, as observed by Nastrom and Tsuda (2001, this issue), in which they always observed anisotropy showing the spectral width in the beam directed perpendicular to the prevailing wind is greater than that in the beam parallel to the wind at both the White Sands, New Mexico and MU radar, Japan sites. The bottom panel of the Fig. 3 shows the comparison of the SNR and spectral width in the north and east beam directions in the mesosphere plotted using the data from September 1995 to August 1999. For this, a total of 49169 points were used using a $1.2 \mathrm{~km}$ range resolution between the $70-80 \mathrm{~km}$ height region. In the mesosphere, it is seen that the east beam SNR is more than the north beam SNR for about $20-30 \%$ of the time and the north beam SNR is more than the east SNR for about $30-40 \%$ of the time and during the remaining time, it is showing isotropy. The spectral width also shows similar features to the SNR. The anisotropies in these Doppler parameters have been seen in past studies and were attributed to aspect sensitivity effects; sometimes those effects are attributed to gravity wave effects (Hocking, 1985). In the present study, the averaged spectral width from all four off-vertical directions has been taken since it is showing anisotropy, sometimes more in the north beam spectral width and sometimes more in the east beam spectral width. On average, all the beams will give more or less the same intensities.

\subsection{Monthly variations}

To study monthly and seasonal variations of eddy diffusivity, $K$ as seen in the troposphere and lower stratosphere routinely monitored Indian MST radar observations during the time period of September 1995 to August 1998 are used. The radar data collected for about 30 minutes a day at around 1700 LT (1200 GMT) is averaged and taken as the representative of that day. In the mesosphere, data collected with the MST radar from September 1995 to August 1999 are used to study the monthly and seasonal variations of eddy diffusivity. Data obtained due to spurious echoes (meteors) are often 

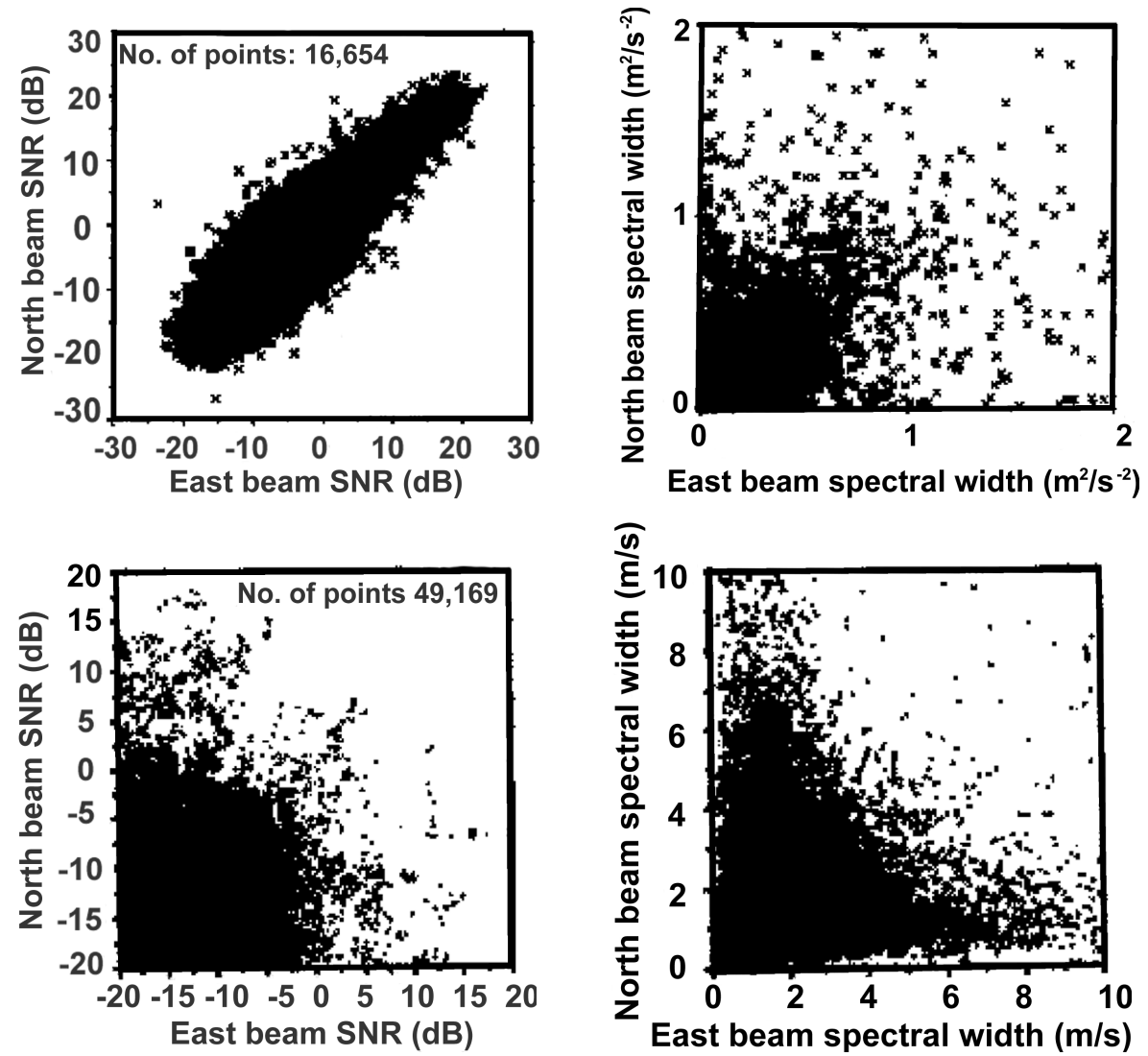

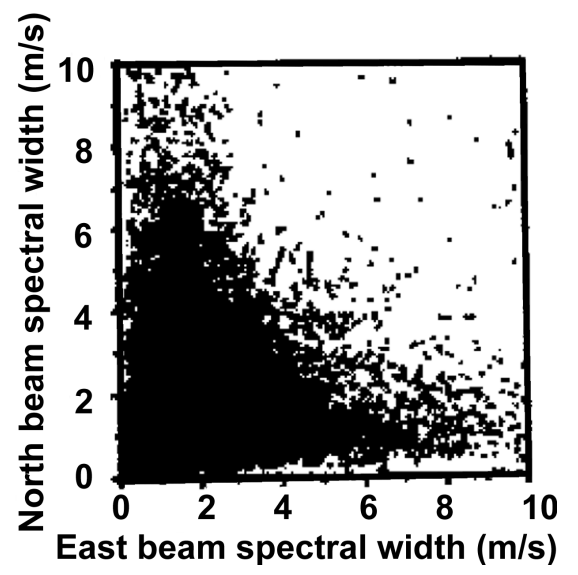

Fig. 3. Comparison of the SNR and spectral width in the north and east directions. Top panel is for the troposphere and lower stratosphere, and bottom panel is for the mesosphere. Note that the spectral width units for the lower atmosphere are squared. detected and are removed for further analysis.

Figure 4 shows contour plots of the monthly median of vertical eddy diffusivity $K$, as observed with the Indian MST radar in the troposphere and lower stratosphere during the time period of 1995-1998. In almost all the months in the observational period, $K$ is found to be at a maximum in the lower heights up to $10 \mathrm{~km}$. During the monsoon and post monsoon months (described in detail in Sect. 4.3), large values of $K$ are observed when compared to winter and summer at most of the heights. The value of $K$ is found to be large in the vicinity of tropical easterly jet stream (TEJ) which prevails over this region during monsoon months. The possible mechanism might be large shears observed both below and above the jet (Rao et al., 2000). Eddy diffusivity values show a high degree of variability during the annual cycle. The variation of $K$ is about 4-6 dB in the lower stratosphere, while it is about $9 \mathrm{~dB}$ in upper troposphere.

Figure 5 shows contour plots of the monthly median of vertical eddy diffusivity $K$, as observed with the Indian MST radar in the mesosphere during the time period of 19951999. During the months of September, October, March, April and July, large values of $K$ are observed at mesospheric heights. A large monthly variability of $K$ up to $6 \mathrm{~dB}$ is observed during these months when compared to the winter months. The possible reason for the enhancement of $K$ during these months might be the turbulence created by the breaking of gravity waves. It is now generally accepted that the dynamics and structure of the mesosphere are strongly influenced by the propagation of gravity waves into this region. Gravity waves originating in the troposphere can propagate into higher altitudes with an increase in amplitude (Fritts, 1989). A vertically propagating wave begins to break at the level where there is a sudden change in the temperature lapse rate (Whiteway et al., 1995). At zones of gravity wave breaking, a large amount of energy and momentum are lost by the waves. The temperature profile obtained from the co-located Lidar observations shows an inversion of about 20-30 K in the height region of $73-76 \mathrm{~km}$ (Ratnam et al., 2001). The percentage occurrence of the height of the temperature inversion and the height of the maximum echo power are seen to be matching well during our study. It is also found that the percentage occurrence of the temperature inversion shows a peak during these months. These studies support the existence of a maximum of $K$ values during these months and the source could be the gravity wave breaking.

\subsection{Seasonal variations}

Figure 6 shows the vertical profiles of $K$ observed during four seasons (June-August: Monsoon; SeptemberNovember: post monsoon; December-February: winter and March-May: summer) in the troposphere and lower stratosphere. The vertical profiles of the seasonal medians of $K$ show large variations from year-to-year above $12 \mathrm{~km}$ in all the seasons. Above $14 \mathrm{~km}$, the value of $K$ is found to be 


\section{(a) $1996-96$}

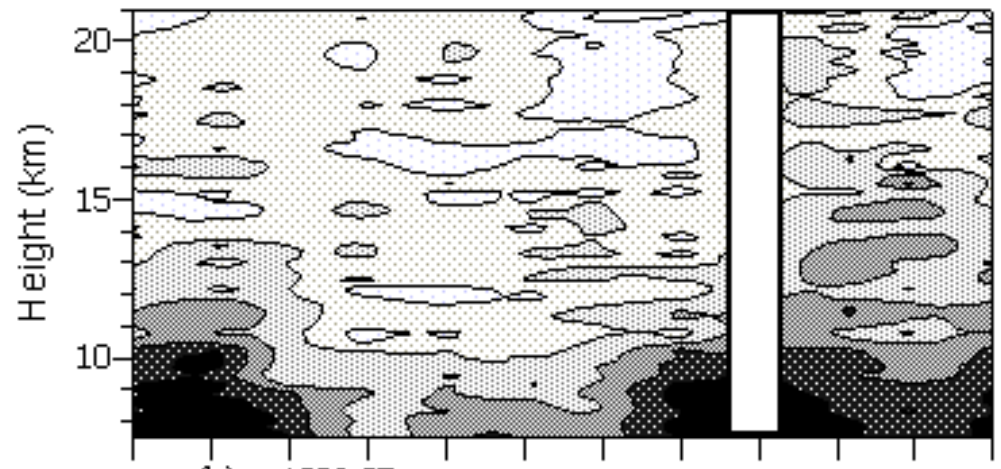

(b) $1996-97$

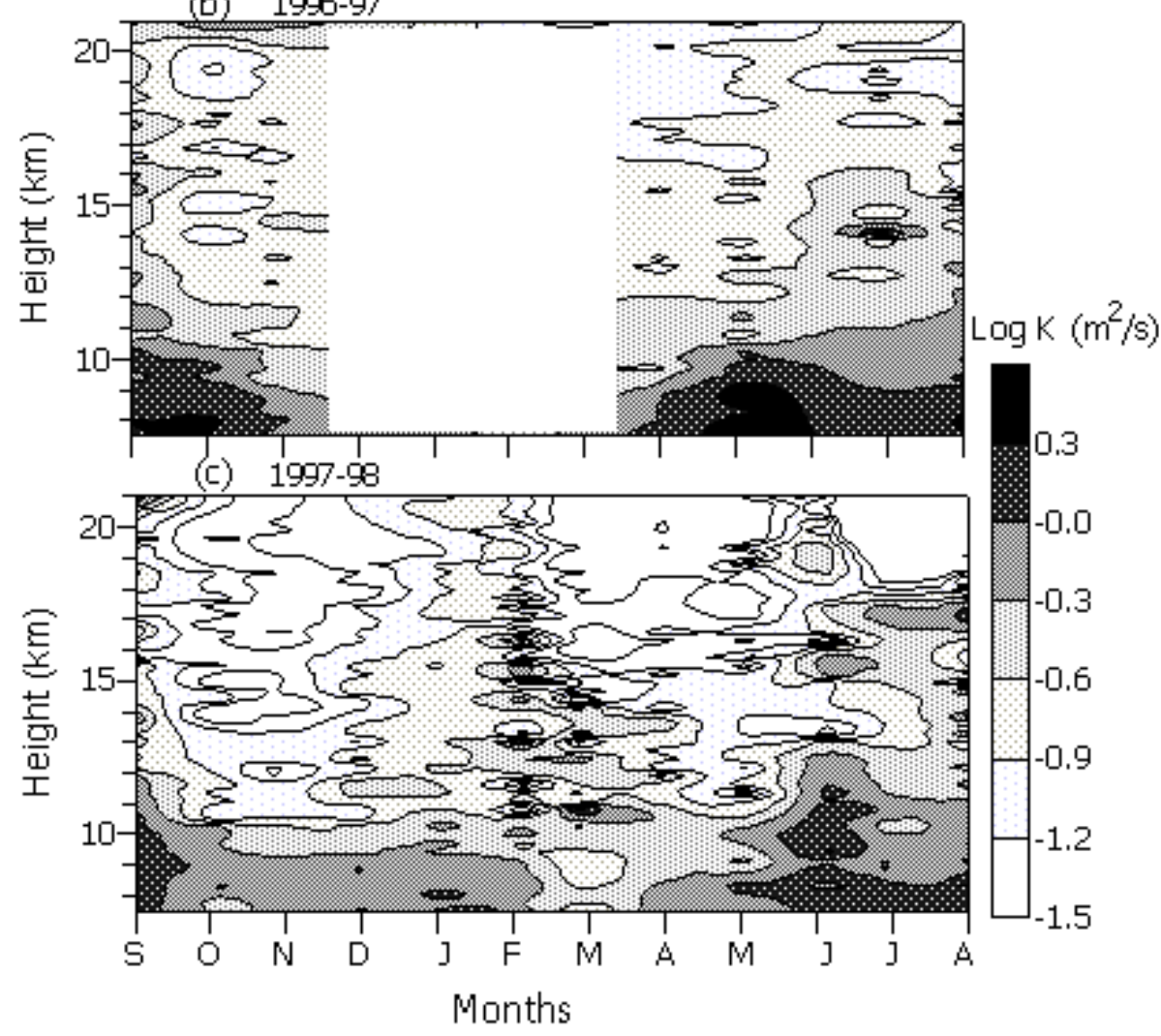

Fig. 4. The contour plots of the monthly median of the vertical eddy diffusivity $K$ observed with the Indian MST radar in the troposphere and lower stratosphere during (a) Sep 1995 to Aug 1996, (b) Sep 1996 to Aug 1997 and (c) Sep 1997 to Aug 1998. less in 1998 than in other years in all the seasons. A maximum variation of the order of about $4-5 \mathrm{~dB}$ is observed in $K$ during the post monsoon and summer seasons (in the height region of $14-21 \mathrm{~km}$ ), while a minimum is seen in the winter and monsoon seasons with a maximum of about $2 \mathrm{~dB}$. From the figure it is also observed that, in general, the value of $K$ decreases with increasing height in all the seasons. Maximum values of $K$ are observed in lower heights and minimum values are observed at the tropopause and in the lower stratosphere. The tropopause height in different seasons (arrow) is also given from which the value of $K$ is observed to be at a minimum at the tropopause and remains constant above it. The observed maximum and minimum values of $l o g$ $K$ are about 0.4 and $-1.3 \mathrm{~m}^{2} \mathrm{~s}^{-1}$, respectively, in the height region of $7.5-21 \mathrm{~km}$.

The value of $K$ obtained in the present study compares well with those values available in the literature. However, the trends differ considerably. Fukao et al. (1994) observed increasing values of $K$ with height up to $12 \mathrm{~km}$ from their seasonal study of $K$ using three years of the data collected with the MU radar. On the other hand, Nastrom and Eaton (1997) found that the values of $K$ decrease with height in the troposphere using the WSMR data at New Mexico. However, a good agreement is seen between the values of $K$ at these two sites in the stratosphere. The differences in $K$ in the troposphere are attributed to different meteorological conditions normally occurring at these two sites (Nastrom and Eaton, 1997). The estimated values of $K$ are also compared with those determined by other methods. A model profile by Massie and Hunten (1981) shows a value of 10 $\mathrm{m}^{2} \mathrm{~s}^{-1}$ throughout the troposphere, which is more than the observed value of $K$ in the present study. This value reaches 

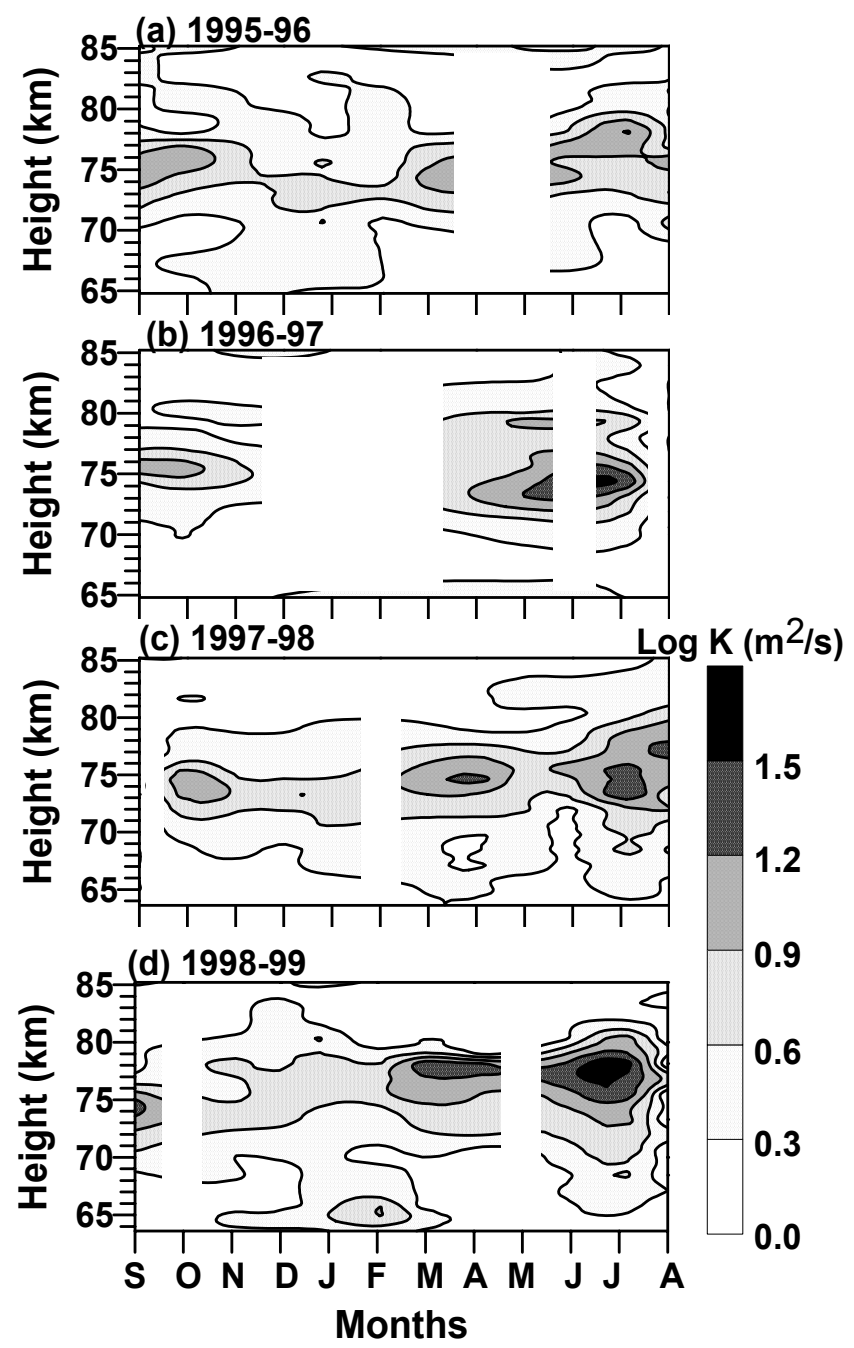

Fig. 5. Same as Fig. 4, but for the mesosphere during (a) Sep. 1995 to Aug. 1996, (b) Sep. 1996 to Aug. 1997, (c) Sep. 1997 to Aug. 1998 and (d) Sep. 1998 to Aug. 1999.

0.5 near $17 \mathrm{~km}$ and is nearly constant up to $20 \mathrm{~km}$. Lilly et al. (1974), using aircraft observations, reported $K$ values of $0.3-0.9 \mathrm{~m}^{2} \mathrm{~s}^{-1}$ in the lower stratosphere.

The vertical profiles of the seasonal median of $K$ observed during four seasons (September-October: fall equinox; November-February: winter; March-April: spring equinox; May-August: summer) at mesospheric heights are shown in Fig. 7. From the figure it is clear that the values of $K$ become large in the mesosphere when compared to the troposphere and lower stratosphere. In the mesosphere, the value of $K$ gradually increases with height and shows a peak at around $75-76 \mathrm{~km}$ in all the seasons and again decreases above 75 $\mathrm{km}$. The reason for the enhancement in the value of $K$ around $75 \mathrm{~km}$ could be the gravity wave breaking, which is already discussed in Sect. 4.2 and also reported by several investigators. These waves will deposit momentum, decelerate the local wind and the breaking then produces turbulence inside and above the inversion layer (Hauchecorne et al., 1987). This turbulence is observed to be a maximum at the layer and slowly decreases above and below this height region.

The seasonal maximum values of $K$ in the mesosphere are observed during the summer (especially in July), similar to that of the troposphere and lower stratosphere, which show a maximum during the monsoon (especially in July) season. But the values of $K$ in the mesosphere are very large when compared to that of the lower atmosphere. The maximum and minimum values of $K$ are observed during the summer and winter, respectively. The percentage occurrence of temperature inversions show a maximum during the summer and a minimum during the winter season (Ratnam et al., 2001) and match well with the occurrence of the maximum and minimum values of $K$. The results obtained in the present study compare well with those reported by Fukao et al. (1994). Their observations of $K$ using MU radar show a summer maximum and a winter minimum similar to that obtained in the present study. The difference between these two observations is that the values at the mesospheric heights of their observations show a continuous increase with height, but we observed a peak at around the $75 \mathrm{~km}$ height region. Other differences are that the values reported by them are quite high when compared with the values over this region. One item should be noted here: the average mesopause height at this region is between $83-86 \mathrm{~km}$ yet radar echoes are not frequently seen at these heights. But the enhancement in the values of $K$ at $75 \mathrm{~km}$ might be due to secondary maximum temperature (inversions of approximately 20-30 $K$ enhancement, assuming mesopause as a first maximum) that is frequently observed at this height using co-located lidar (Ratnam et al., 2001).

\subsection{Annual variations}

The vertical profiles of the annual median of the vertical eddy diffusivity $K$ in the troposphere, lower stratosphere (left panel) and mesosphere (right panel) are shown in Fig. 8. From the figure it is clear that there is not much annual variation in either the troposphere, lower stratosphere or the mesosphere. However, a small variation of about $1-2 \mathrm{~dB}$ and $1 \mathrm{~dB}$ is observed above $14 \mathrm{~km}$ and above $75 \mathrm{~km}$, respectively. On the average, the maximum and minimum values of $\log K$ in the troposphere and lower stratosphere are 0.25 and $-1.3 \mathrm{~m}^{2} \mathrm{~s}^{-1}$, respectively, whereas in the mesosphere, the maximum and minimum values of $\log K$ are 0.7 and 0.3 $\mathrm{m}^{2} \mathrm{~s}^{-1}$, respectively. In general, there is a decreasing trend in the lower atmosphere up to around $18 \mathrm{~km}$, whereas above $18 \mathrm{~km}$, it is remaining nearly constant with height. In the mesosphere, it increases up to a certain height $(75 \mathrm{~km})$ and again decreases above that height. The values of $K$ in the troposphere and mesosphere are found to be less than that observed by Fukao et al. (1994).

\section{Summary}

Three years of MST radar data in the troposphere and lower stratosphere and four years of data in the mesosphere are 


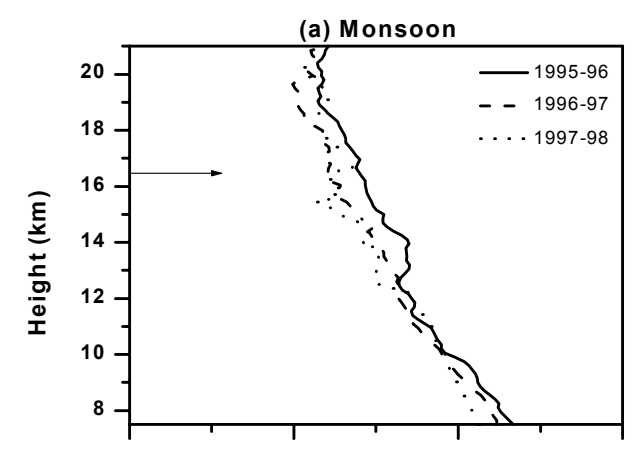

(c) Winter
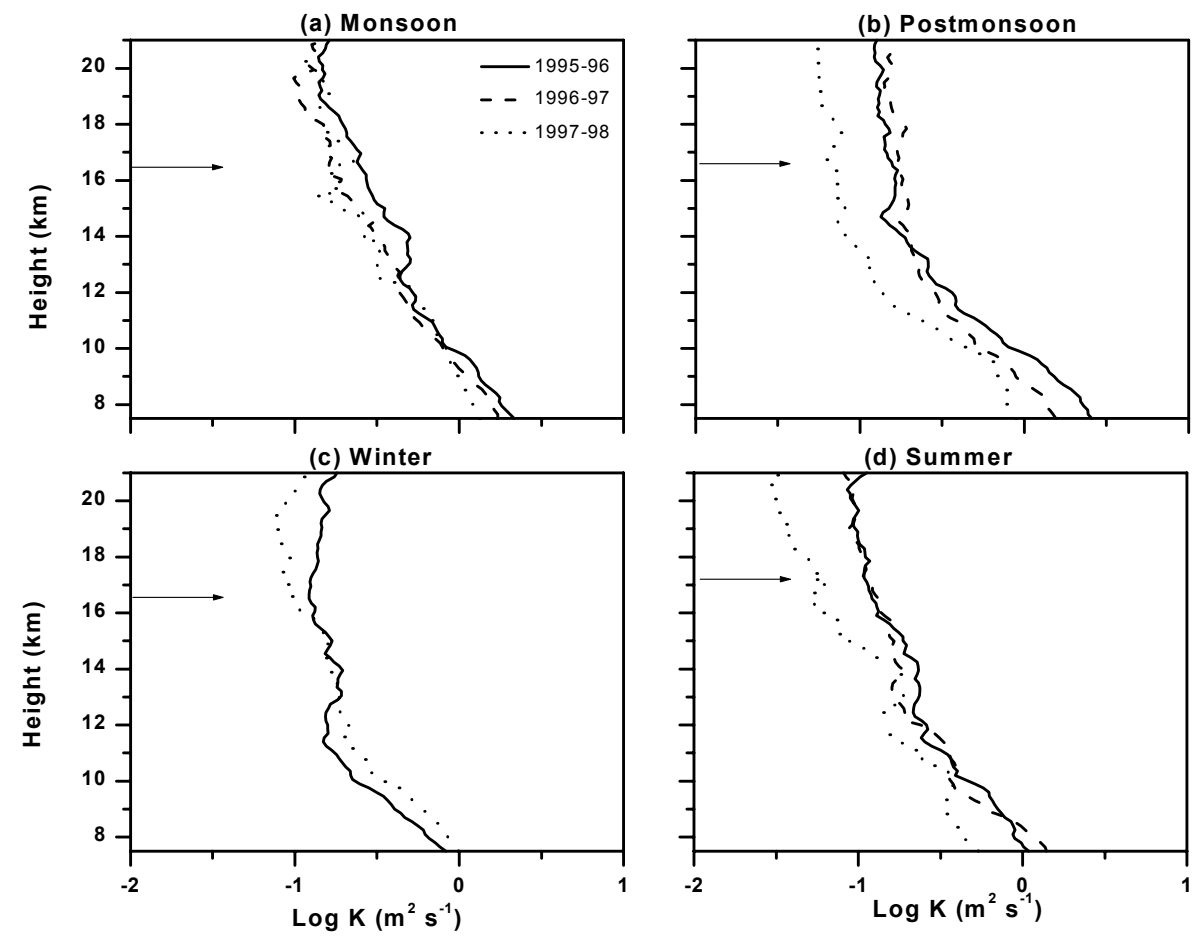

(a) Fall equinox

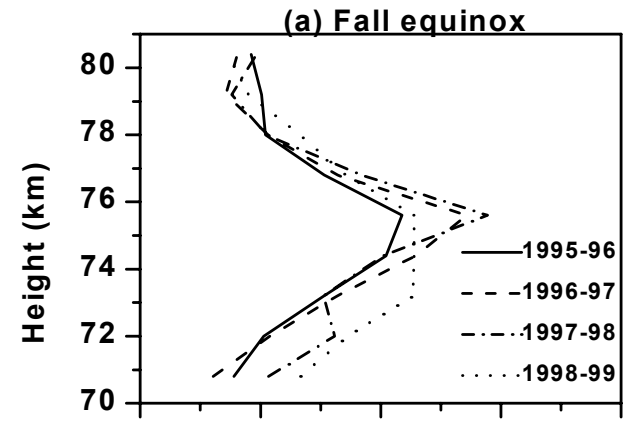

(c) Spring equinox

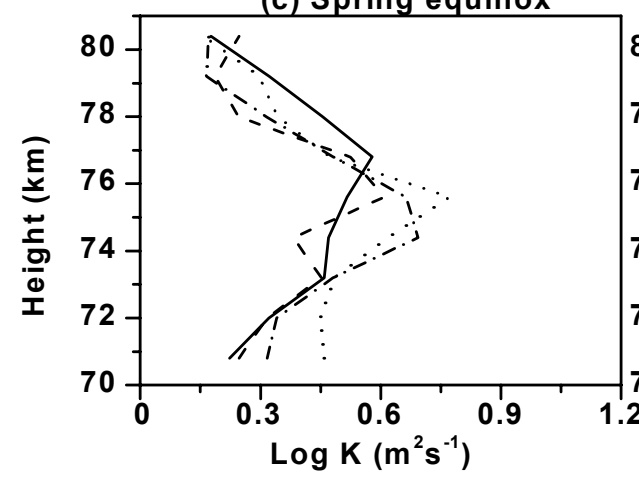

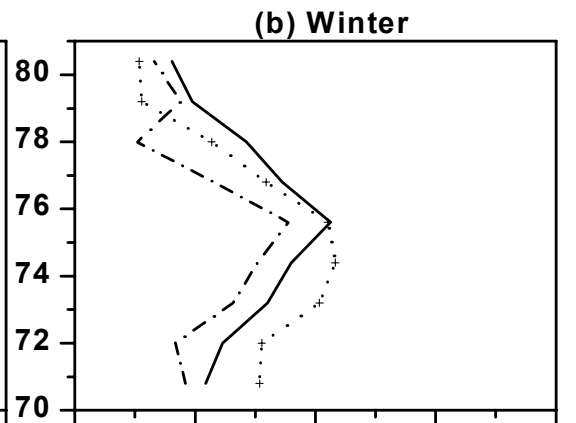

(d) Summer

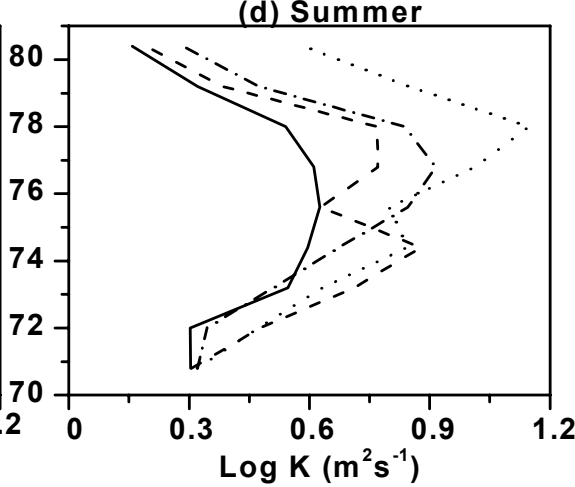

Fig. 7. Vertical profiles of the seasonal median of $K$ observed during four seasons (September-October: fall equinox; November-February: winter; MarchApril: spring equinox; May-August: summer) in the mesosphere.

used to study the vertical variations of the monthly, seasonal and annual median of the eddy diffusivity, $K$. In general, the values of $K$ are found to be larger in the mesosphere than in the troposphere and lower stratosphere. The maximum value of $K$ is seen in the lower heights of the troposphere and in the mesosphere, the value of $K$ increases with altitude up to $75 \mathrm{~km}$ and then decreases above that height. The magni- tude of $\log K$ is found to be $-1.3-0.25 \mathrm{~m}^{2} \mathrm{~s}^{-1}$ and $0.3-$ $0.7 \mathrm{~m}^{2} \mathrm{~s}^{-1}$ in the troposphere and mesosphere, respectively. The value of $K$ is observed to be more in the monsoon and post-monsoon seasons than in the summer and winter below $11 \mathrm{~km}$, while above $11 \mathrm{~km}, K$ is at a maximum in the monsoon season. In the mesosphere, the maximum values of $K$ are seen during the summer followed by equinoxes and at 

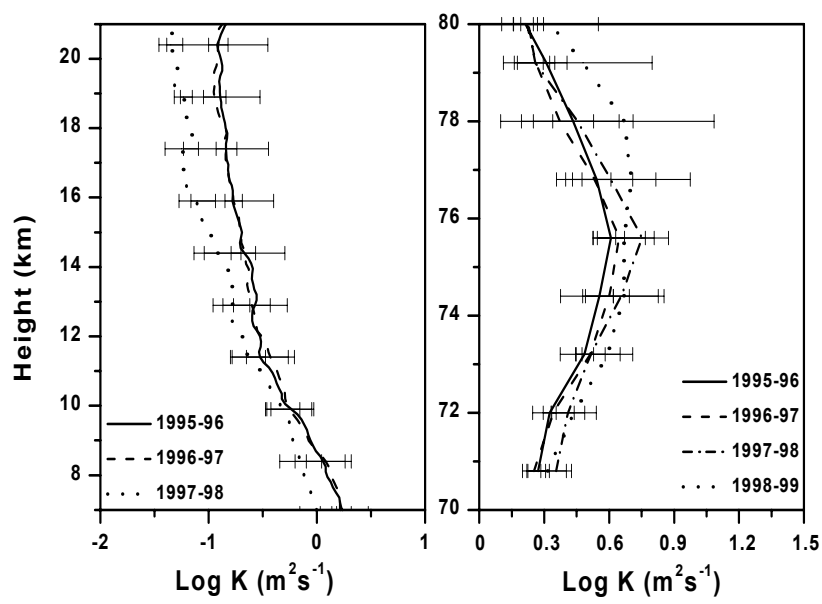

Fig. 8. The vertical profiles of the annual median of the vertical eddy diffusivity $K$ in the troposphere, lower stratosphere (left panel) and in the mesosphere (right panel) observed with Indian MST radar.

a minimum during the winter. The values reported here are somewhat less than that of the reported values at other places using VHF radars. In the troposphere, the enhancement of $K$ in the monsoon season is thought to be due to convective activity observed during those times. The summer maximum in the mesosphere is thought to be due to the breaking of gravity waves in that season, though we have not shown this here and it can be found elsewhere (Ratnam et al., 2001). In brief, from the coordinated observations of the MST radar and lidar, we observed that the gravity wave activity is more in the summer followed by equinoxes and at a minimum during the winter. This matches well with the summer maximum and winter minimum of $K$. Comparison of Doppler spectral parameters in different beam directions shows anisotropy in both the SNR and spectral widths in the mesosphere, whereas the comparison shows isotropy in SNR and anisotropy in the spectral widths in the troposphere and lower stratosphere.

Acknowledgement. The authors wish to thank UGC-SVU Centre for MST Radar Applications, S. V. University, Tirupati for providing necessary facilities to carry out the research work. Authors express their gratitude to the Lidar team for conducting experiments and providing the data. Two of the authors (MVR and TNR) are thankful to CSIR for providing Senior Research Fellowships. The authors express their gratitude for the kind suggestions given by A. K. Patra, S. Thulasiraman and P. B. Rao.

Topical Editor D. Murtagh thanks two referees for their help in evaluating this paper.

\section{References}

Atlas, D., Srivastava, R. C., and Sloss, P. W., Wind shear and reflectivity gradient effects on Doppler radar spectra: II, J. Appl. Meteorol., 8, 384, 1969.

Cohn, S. A., Radar measurements of turbulent eddy dissipation rate in the troposphere: a comparison of techniques, J. Atmos. Ocean Technol., 12, 85, 1995.

Frisch, A. S. and Clifford, S. F., A study of convection capped by a stable layer using Doppler radar and Acoustic echo sounders, J. Atmos. Sci., 31, 1622, 1974.

Fritts, D. C., A review of gravity wave saturation processes, effects and variability in the middle atmosphere, Pageoph, 130, 343, 1989.

Fukao, S., Yamanaka, M. D., Naoki Ao, Hocking, W. K., Sato, T., Yamamoto, M., Nakamura, T., Tsuda, T., and Kato, S., Seasonal variability of vertical eddy diffusivity in the middle atmosphere 1. Three-year observations by the middle and upper atmosphere radar, J. Geophys. Res., 99, 18973, 1994.

Hauchecorne. A., Chanin, M. L., and Wilson, R., Mesospheric temperature inversion and gravity wave breaking, Geophys. Res. Let., 14, 933, 1987.

Hildebrand, P. H. and Sekhon, R. S., Objective determination of the noise level in Doppler spectra, J. Appl. Meteorol., 13, 808, 1974.

Hocking, W. K., On the extraction of atmospheric turbulence parameters from radar backscatter Doppler spectra-1. Theory, J. Atmos. Terr. Phys., 45, 89, 1983.

Hocking, W. K., Measurements of turbulent energy dissipation rate in the middle atmosphere by radar technique: A review, Radio Sci., 20, 1403, 1985.

Hocking, W. K., Observations and measurements of turbulence in the middle atmosphere with a VHF radar, J. Atmos. Terr. Phys., 48, 655, 1986

Hocking, W. K., Two years of continuous measurements of turbulence parameters in the upper mesosphere and lower thermosphere made with a 2-MHz radar, J. Geophys. Res., 93, 2475, 1988.

Hocking, W. K., Recent advances in radar instruments and techniques for studies of the mesosphere, stratosphere and troposphere, Radio Sci., 32, 2241, 1997.

Kishore, P., Atmospheric studies using Indian MST radar-Winds and Turbulence parameters, Ph.D. Thesis, S. V. University, Tirupati, India, 1995.

Lilly, D. K., Waco, D. E., and Adelfang, S. I., Stratospheric mixing estimated from high-altitude turbulence measurements, J. Appl. Meteorol., 13, 488, 1974.

Lübken, F. J., Von Zahn, U., Thrane, E. V., Blix, T. A., Kokin, G. A., and Pachomov, S. V., In-situ measurements of turbulence energy dissipation rates and eddy diffusion coefficients during MAP/WINE, J. Atmos. Terr. Phys., 49, 763, 1987.

Massie, S. T. and Hunten, D. M., Stratospheric eddy diffusion coefficients from tracer data, J. Geophys. Res., 86, 9859, 1981.

Nastrom, G. D., Doppler radar spectral width broadening due to beam width and wind shear, Ann. Geophysicae, 15, 786, 1997.

Nastrom, G. D. and Eaton, F. D., A brief climatology of eddy diffusivities over White Sands Missile Range, New Mexico, J. Geophys. Res., 102, 29819, 1997.

Nastrom, G. D. and Tsuda, T., Anisotropy of Doppler spectral parameters in the MU and White Sands VHF radar observations, Proceedings of the Ninth International Workshop on Technical and Scientific Aspects of MST radar, Tolouse, France, March 13-18, 2000, edited by Belva Edwards, 2001.

Rao, D. N., Kishore, P., Rao, T. N., Rao, S. V. B., Reddy, K. K., Yarraiah, M., and Hareesh, M., Studies on refractivity structure constant, eddy dissipation rate, and momentum flux at a tropical latitude, Radio Sci., 32, 1375, 1997.

Rao, D. N., Rao, T. N., Ratnam, M. V., Thulasiraman, S., Rao, S. V. B., Rao, P. B., and Srinivasulu, P., Diurnal and seasonal 
variability of turbulence parameters observed with Indian MST Radar, Radio Sci., in press, 2001.

Rao, D. N., Thulasiraman, S., Rao, S. V. B., Rao, T. N., Kishore, P., Ratnam, M. V., and Reddy, K. K., VHF radar observations of tropical easterly jet stream over Gadanki, Adv. Space Res., 26, 943, 2000.

Rao, P. B., Jain, A. R., Kishore, P., Balamuralidharan, P., Damle, S. H., and Viswanathan, G., Indian MST radar, 1. System description and sample vector wind measurements in ST mode, Radio Sci., 30, 1125, 1995.

Ratnam, M. V., Rao, D. N., Rao, T. N., Krishnaiah, M., Kumar, Y. B., Kumar, V. S., and Rao, P. B., MST Radar and Lidar obser- vations for the study of Mesospheric structures over a tropical station, submitted to J. Atmos. Terr. Phys., 2001.

Sato, T. and Woodman, R. F., Fine altitude resolution observations of stratospheric turbulent layers by the Arecibo 430-M. Hz radar, J. Atmos. Sci., 39, 2546, 1982.

Whiteway. J. A. and Carswell, A. I., Lidar observations of gravity wave activity in the upper stratosphere over Toronto, J. Geophys. Res., 100, 14, 113, 1995.

Woodman, R. F. and Guillen, A., Radar observations of winds and turbulence in the stratosphere and mesosphere, J. Atmos. Sci., 31, 493, 1974. 